\title{
METODE PENDIDIKAN ANAK MUSLIM USIA PRASEKOLAH (3 - 6 TAHUN)
}

\author{
Tiy Kusmarrabbi Karo \\ Program Studi Pendidikan Bahasa Arab STAI As-Sunnah Deli Serdang \\ Jl. Medan-Tg. Morawa, Km. 13 G. Darmo, Desa B. Sari, Kec. Tg. Morawa Kab. Deli Serdang \\ Kusma70@yahoo.co.id
}

\begin{abstract}
Abstrak: ilmu mendidik anak merupakan salah satu bekal bagi orang tua yang telah membangun rumah tangga. Tanpa pengetahuan/ilmu mendidik anak, besar kemungkinan, anak-anak kita tidak terdidik, terbina maupun terkader dengan baik. Justru yang akan terjadi adalah fitrah anak yang bertauhid dan berislam sejak dalam kandungan ibu menjadi ternodai hingga hati, pikiran, jiwa, sikap, dan perilaku anak cenderung mengikuti Yahudi, Nasrani, maupun Majusi. Lalai dalam menyiapkan bekal ini, sesal kemudian tak berguna. Tulisan ini mencoba memaparkan metode pendidikan anak muslim usia prasekolah secara ringkas dan lugas, melalui pendidikan aqidah, ibadah, akhlak, pendidikan emphatik, pendidikan jasmani, pendidikan kesehatan, dan pendidikan intelektualitas anak.
\end{abstract}

Kata Kunci: Pendidikan, anak muslim, usia prasekolah.

\section{Pendahuluan}

Anak adalah amanat Allah kepada orang tua, hatinya masih suci bagaikan tambang asli yang masih bersih dari segala corak dan warna. Ia siap dibentuk untuk dijadikan apa saja tergantung keinginan pembentuknya. Jika dibiasakan dan dibina untuk menjadi baik maka ia akan menjadi baik. Kedua orang tua, para guru dan pendidiknya pun akan menuai kebahagiaan di dunia dan di akhirat. Sebaliknya, bila dibiasakan terhadap keburukan dan diabaikan pembinaannya laksana binatang ternak, maka buruklah jadinya dan ia pun akan merugi. Orang 
tua dan para pendidiknya pun akan turut menanggung dosanya. Hal ini senada dengan firman Allah:

Artinya: "Hai orang-orang yang beriman, peliharalah dirimu dan keluargamu dari api neraka yang bahan bakarnya adalah manusia dan batu; penjaganya malaikat-malaikat yang kasar, yang keras, yang tidak mendurhakai Allah terhadap apa yang diperintahkan-Nya kepada mereka dan selalu mengerjakan apa yang diperintahkan.(At Tahrim: 6)

Terhadap ayat ini Ibnu Kasir dalam tafsirnya menjelaskan, bahwa ayat ini menganjurkan kepada setiap individu muslim bertakwa kepada Allah dan perintahkanlah kepada keluargamu untuk bertakwa kepada Allah. Ibnu Kasir menjelaskan bahwa Qatadah mengatakan bahwa engkau perintahkan mereka untuk taat kepada Allah dan engkau cegah mereka dari perbuatan durhaka terhadapNya, dan hendaklah engkau tegakkan terhadap mereka perintah Allah dan engkau anjurkan mereka untuk mengerjakannya serta engkau bantu mereka untuk mengamalkannya. Jika engkau melihat di kalangan keluargamu suatu perbuatan maksiat kepada Allah, maka engkau harus cegah mereka darinya dan engkau larang mereka melakukannya. Hal yang sama juga dikemukakan Ad-Dahlak dan Muqatil, bahwa sudah merupakan suatu kewajiban bagi seorang muslim mengajarkan kepada keluarganya, baik dari kalangan kerabatnya ataupun budakbudaknya, hal-hal yang difardukan oleh Allah dan mengajarkan kepada mereka hal-hal yang dilarang oleh Allah yang harus mereka jauhi. ${ }^{1}$

Berdasarkan ayat tersebut, dipahami bahwa orang tua memiliki kewajiban untuk memelihara diri dan keluarga (anak-anaknya) dari siksaan api neraka. Cara yang dapat dilakukan oleh orang tua ialah mendidiknya, membimbingnya dan mengajari akhlak-akhlak yang baik. Mengenalkannya pendidikan aqidah, ibadah, akhlak, pendidikan emphatik, pendidikan jasmani, pendidikan kesehatan, dan pendidikan intelektualitasnya. Kemudian orang tua harus menjaganya dari pergaulan yang buruk, dan jangan membiasakannya berfoya-foya, jangan pula orang tua menanamkan rasa senang bersolek dan hidup dengan sarana-sarana

${ }^{1}$ Ismail Ibnu Katsir al-Dimasyqi, Tafsir Al Qur'an al-Karim, Jilid 28, (Kairo: Maktabah Aulad al-Syaikh li at-Turats, 2000), h. 416. 
kemewahan pada diri anak, sebab kelak anak akan menyia-nyiakan umurnya hanya untuk mencari kemewahan jika ia tumbuh menjadi dewasa, sehingga ia akan binasa untuk selamanya. Akan tetapi seharusnya orang tua sejak dini mulai mengawasi pertumbuhannya dengan cermat dan bijaksana sesuai dengan tuntutan pendidikan Islam.

Dari uraian di atas kiranya dapat disebutkan bahwa tujuan pendidikan anak usia dini dalam pandangan Islam adalah memelihara, membantu pertumbuhan dan perkembangan fitrah manusia yang dimiliki anak, sehingga jiwa anak yang lahir dalam kondisi fitrah tidak terkotori oleh kehidupan duniawi yang dapat menjadikan anak sebagai Yahudi, Nasrani atau Majusi. Atau dengan kata lain bahwa pendidikan anak usia dini dalam pendidikan Islam bertujuan untuk menanamkan nilai-nilai keislaman kepada anak sejak dini, sehinga dalam perkembangan selanjutnya anak menjadi manusia muslim yang kāffah, yang beriman dan bertaqwa kepada Allah SWT. Hidupnya terhindar dari kemaksiatan, dan dihiasi dengan ketaatan dan kepatuhan serta oleh amal soleh yang tiada hentinya. Kondisi seperti inilah yang dikehendaki oleh pendidikan Islam, sehingga kelak akan mengantarkan peserta didik pada kehidupan yang bahagia di dunia maupun di akhirat.

\section{Pengertian Anak Prasekolah}

Yang dimaksudkan dengan anak prasekolah adalah mereka yang berusia antara 3-6 tahun menurut Biechler dan Snowman dalam soemiarti. ${ }^{2}$ Mereka biasanya mengikuti program prasekolah dan kinderganten. Sedangkan di Indonesia, umumnya mereka mengikuti program Tempat Penitipan Anak (3 bulan - 5 tahun) dan Kelompok Bermain (usia 3 tahun), sedangkan pada usia 4-6 tahun biasanya mereka mengikuti program Taman Kanak-Kanak.

Masa Balita akhir dalam istilah psikologi disebut dengan masa kanakkanak awal yaitu masa yang dimulai pada akhir masa bayi (usia 2-5) tahun. Pada perkembangan anak normal awal masa kanak-kanak, anak sudah mempunyai

2 Soemiarti Patmonodewo, Pendidikan Anak Prasekolah (Jakarta: Rineka Cipta, 2008), Cet. 2, h. 19. 
kemampuan untuk bisa berjalan dengan baik dan sudah mulai dapat mengkomunikasikan keinginannya, pikirannya, dengan menggunakan bahasa lisan. $^{3}$

Menurut Erik Erikson, bahwa : "Perkembangan kepribadian sesorang dengan titik berat pada perkembangan psikologi tahapan (0-1 tahun berada tahapan oral sensorik, tahapan (3-6) tahun mereka berada dalam tahapan dengan krisis autonomy versus shame dan doubt."4

Sedangkan Piaget mengatakan : "Perkembangan kognitif, perkembangan dari tahapan sensorimotor (0-2 tahun), praoperasional (2-7 tahun), operasional konkret (7-12 tahun), maka perkembangan kognitif anak masa prasekolah pada tahap praoperasional. ${ }^{5}$

Pada dasarnya, pendidikan prasekolah (preschool) adalah pendidikan untuk membantu pertumbuhan dan perkembangan jasmani rohani anak didik di luar lingkungan keluarga sebelum memasuki pendidikan dasar. ${ }^{6}$

\section{Aspek Pendidikan Anak Muslim Usia Prasekolah (3-6 Tahun)}

Agar orang tua dapat bijaksana dan pandai mendidik anak-anak, maka mereka harus mengenali terlebih dahulu kemampuan anak pada fase ini, diantaranya:

1. Mampu membaca tulisan Arab (Alquran) dan bahasa Indonesia juga bahasa lainnya.

2. Menghafal do'a-do'a pendek dan surat pendek juz amma'.

3. Kemampuan sosialisasi berkembang dengan pesat, memiliki teman bermain, dapat diskusi.

4. Mempraktekkan sedikit demi sedikit apa yang telah mereka pelajari. Misalnya, do'a hendak tidur, do'a naik kendaraan, salam ketika masuk rumah.

5. Menghormati orang tua dan

${ }^{3}$ Endang Poerwanti dan Nur Widodo, Perkembangan Peserta Didik (Malang : UMM Press, 2002), Cet. II, h. 78.

${ }^{4}$ Soemiarti Patmonodewo, loc.cit.

5 Ibid.

${ }^{6}$ Ismail SM (eds), Paradigma Pendidikan Islam, (Yogyakarta : Pustaka Pelajar, 2001), h. 216. 
6. Meminta maaf.

Adapun aspek-aspek pendidikan anak muslim prasekolah meliputi pendidikan aqidah, ibadah, akhlak, pendidikan kemasyarakatan, pendidikan jasmani, dan pendidikan pembentukan intelektualitas anak.

\section{Pendidikan Aqidah}

Aqidah Islamiyah - beriman kepada Allah swt, para Malaikat-Nya, Kitabkitab-Nya, para Rasul-Nya, beriman kepada Hari Akhir dan beriman kepada qadha dan qadar yang baik maupun yang buruk - memiliki keistimewaan bahwa kesemuanya itu merupakan sesuatu yang gaib. Seseorang akan menghadapi kebingungan bagaimana ia harus memaparkan semua ini kepada seorang anak dan bagaimana pula seorang anak dapat berinteraksi dengan hal ini? bagaimana membuat hal ini menjadi sederhana? Bagaimana cara memaparkannya di hadapan anak?

Muhammad Ibnu Abdul Hafidh Suwaid menjelaskan hal-hal yang harus diperhatikan dalam memberikan materi pendidikan aqidah kepada anak adalah sebagai berikut:

1. Pen-talqin-an kalimat tauhid.

2. Cinta kepada Allah, merasa diawasi Allah, meminta pertolongan-Nya, serta beriman kepada qadha dan qadar.

3. Mencintai Rasulullah, keluarganya, dan para sahabatnya.

4. Mengajarkan alquran kepada Anak

5. Menanamkan Aqidah yang kuat dan kerelaan berkorban ${ }^{7}$

Senada dengan hal di atas Suroso Abdussalam menambahkan dua point penting terkait pendidikan aqidah untuk anak-anak muslim yaitu:

1. Menghafal ayat-ayat dan Hadis pendek

2. Membaca Alquran dan tafsirnya, membaca hadis dan maknanya, serta sibuk dengan tugas-tugas ibadah. ${ }^{8}$

${ }^{7}$ Muhammad Ibnu Abdul Hafidh Suwaid, Manhaj Tarbiyah Nabawiyah Lith Thifli, Edisi Indonesia, "Cara Nabi Mendidik Anak", Penerjemah: Hamim Thohari et al. (Jakarta Timur: Al'Itishom Cahaya Umat, Cet. II, 2008), h. 157. 
Imam Al-Ghazali telah memberikan penekanan tersendiri agar orang tua memberikan perhatian khusus terhadap aqidah anaknya serta men-talqin-kannya sedini mungkin agar anak dapat tumbuh di atas landasan aqidah. Ia mengatakan, "Ketahuilah bahwa apa yang telah kami ungkapkan dalam penjelasan aqidah seyogianya diberikan kepada anak sejak awal masa pertumbuhannya, agar ia benar-benar dapat menghafalnya dengan baik, sehingga sedikit demi sedikit, di masa pertumbuhannya, ia akan menyingkap makna yang terkandung di dalamnya. Maka, mulailah dengan membuatnya hafal, kemudian memahami dan membuatnya percaya, yakin, serta membenarkannya. Hal ini bisa terwujud pada diri anak tanpa harus memberikan bukti yang nyata. Ini merupakan bagian dari karunia yang Allah berikan kepada hati manusia. Dia telah melapangkan hatinya untuk dapat menerima keimanan di awal masa pertumbuhannya tanpa perlu mengungkapkan argumentasi dan bukti yang nyata." 9

\section{Pendidikan Ibadah}

Pembinaan Ibadah merupakan penyempurnaan dari pembinaan aqidah. Juga merupakan cerminan dari aqidah. Ketika anak telah memenuhi panggilan Rabbnya dan melaksanakan perintah-perintah-Nya, berarti dia telah menyambut kecenderungan fithrah yang ada di dalam jiwanya (jalan taqwa), sehingga dia akan dapat menyiraminya.

Masa kanak-kanak adalah masa persiapan, latihan, dan pembiasaan untuk menyambut masa bembebanan kewajiban setelah baligh. Sehingga kelak pelaksanaan kewajiban terasa mudah, ringan, dan mempunyai kesiapan yang matang untuk menyelami kehidupan dengan penuh keyakinan.

Ibadah memberikan pengaruh yang mengagumkan, yakni:

1. Membuat anak selalu merasa berhubungan dengan Allah.

2. Meredam gejolak kejiwaan dan mengendalikan hawa nafsu, sehingga jiwa akan lurus.

\footnotetext{
${ }^{8}$ Suroso Abdussalam, Strategi Menjadi Orang Tua Bijak dan Pintar (Medokan: Sukses Publishing, 2012), h. 125-126.

${ }^{9}$ Imam al-Ghazali, Al-Ihya fi 'Ulumu al-Din, Juz ke-1. h. 97.
} 
3. Hatinya akan senantiasa tenang (seperti ketika dia membaca atau mendengarka alquran, melaksanakan shalat atau mendengarkan adzan, termasuk adzan Maghrib saat berbuka puasa).

4. Menambah kekuatan dan gairah aktivitasnya.

Ini semua dapat dimulai dengan melakukan pendidikan yang Islami. Upaya-upaya yang dapat kita lakukan kepada anak dalam pendidikan ibadah ini misalnya:

1. Mengajarkan anak tentang shalat.

2. Sebaiknya ikut bersama orang tua melaksanakan shalat. Orang tua dengan sabar membimbing dan tidak menuntut terlalu banyak. Kecuali jika anak sudah berumur sepuluh tahun, maka perintah shalat sudah tidak ada toleransi lagi.

3. Di bulan ramadhan, latihlah dia puasa, bertahap, tidak langsung puasa satu hari penuh.

4. Ajari juga kepada anak untuk senantiasa member shodaqah atau mengeluarkan zakat. Semoga anak-anak menjadi terbiasa dengan amalanamalan ibadah tersebut. ${ }^{10}$

Bila kita perhatikan bimbingan-bimbingan Nabi saw. maka kita akan menemukan bahwa beliau memfokuskan pembinaan anak pada lima pilar tersebut di atas.

\section{Pendidikan Kemasyarakatan}

Tujuan dari pendidikan kemasyarakatan bagi anak adalah agar: Anak dapat bergaul dan berperan positif dalam lingkungan masyarakatnya, baik berhubungan dengan orang dewasa maupun teman-teman sebaya.

Jenis-jenis kegiatan yang dapat membantu anak dalam bersosialisasi dengan lingkungan yakni:

1. Mengajak anak menghadiri majelis orang dewasa.

Tujuannya untuk mengetahui kekurangan dan kebutuhan-kebutuhan anak.

2. Menyuruh anak melaksanakan tugas rumah.

\footnotetext{
${ }^{10}$ Suroso Abdussalam, Strategi Menjadi Orang Tua, h. 133-135.
} 
Rasulullah saw. pernah meminta kepada Anas bin Malik untuk melayani keperluan beliau. Sehingga dia dapat mengenal masalah-masalah kehidupan yang belum pernah dia ketahui dan anak akan bangga dengan pengalaman baru yang telah dia dapatkan.

3. Membiasakan anak mengucapkan salam.

Rasulullah saw. dan sahabatnya memberikan beberapa cara yang lembut dalam menanamkan sunnah salam ini dalam jiwa anak. Anas pernah melewati sekumpulan anak kecil, lalu member salam kepada mereka. Sesudah itu Ibnu Abbas berkata, “Adalah Rasulullah saw. melakukan hal yang demikian itu."

Anak dianjurkan salam kepada kedua orang tuanya, orang dewasa, juga ketika akan masuk rumah.

4. Menjenguk anak yang sakit.

Ketika seorang anak, di mana ia masih dalam kondisi fitrah dan bersih melihat orang-orang dewasa menjenguknya ketika ia sakit maka ia selanjutnya akan membiasakan kebiasaan yang baik.

5. Memilihkan teman yang baik untuk anak.

Jika kedua orang tua pandai-pandai memilihkan teman yang shalih bagi anak mereka maka mereka berarti membuka pintu pendidikan dalam memperbaiki dan mengembangkan anak tersebut.

6. Menghadiri acara atau perayaan yang disyariatkan.

Rasulullah saw. di masa hidupnya menyetujui kehadiran anak-anak dalam acara pesta pernikahan dengan itu akan terbentuk hubungan sosial kemasyarakatan anak. Juga dapat dilakukan dengan mengajak mereka ke tempattempat pertemuan, majelis-majelis, tempat-tempat yang penuh kegembiraan. Begitu juga tidak mengapa untuk mengajaknya ke tempat-tempat hiburan atau wisata (yang tidak melanggar syariat).

\section{Pendidikan Akhlak}

Akhlaq berasal dari kata khuluq yang artinya bentuk jiwa atau kebiasaan seseorang yang berbentuk adab-adab/etika. Masa kanak-kanak adalah masa membutuhkan bimbingan dan perhatian. Dia akan tumbuh menurut apa yang 
dibiasakan kepadanya ketika kecil. Jiwa polosnya akan menerima bentuk perangai apapun yang dipahatkan kepadanya. Selanjutnya pahatan itu terus meluas sedikit demi sedikit hingga akhirnya meliputi seluruh jiwa dan menjadi tabiat. Adab-adab yang dimaksud adalah:

1. Adab-adab kepada orang tua.

2. Adab berbicara dengan orang tua.

3. Adab terhadap orang alim.

4. Adab menghargai orang lain.

5. Adab persaudaraan.

6. Adab bertetangga.

7. Adab meminta izin.

8. Adab makan.

9. Kejujuran.

10. Amanah.

11. Menjaga rahasia.

12. Lapang dada dan tidak mendengki.

13. Dan adab-adab lainnya.

\section{Pendidikan Jasmani}

Masa anak-anak adalah masa pertumbuhan otot dan tulang serta pertumbuhan jasmani seutuhnya. Setelah periode ini, tubuh sulit untuk berkembang lagi atau ditingkatkan kepada yang lebih baik. Bermain dan olahraga dapat membantu perkembangan jasmani anak, terutama permainan yang mendidik.

Para ulama sangat memahami urgensi bermain pada anak dan membentuk fisiknya. Imam Al-Ghazali berkata, "Sebaiknya anak diberikan kesempatan untuk bermain setelah mereka selesai belajar di sekolah-sekolah untuk melepaskan kelelahan dan ketegangannya ketika belajar dengan batasan, permainan yang dilakukan tidak melelahkannya. Karena melarang dan mencegah anak dari bermain dan menenggelamkannya terus-menerus dalam belajar, akan mematikan hatinya, memandulkan kecerdasannya, dan kehidupan terasa sempit baginya. Hal 
itu akan menyebabkannya mencari berbagai cara untuk berbebas dari kekangan."11

Pendidikan jasmani/fisik anak yang dianjurkan oleh Nabi adalah:

1. Belajar berenang, memanah, dan berkuda.

2. Perlombaan olahraga antar anak.

3. Permainan orang dewasa bersama anak-anak.

4. Bermain bersama anak-anak sebaya. ${ }^{12}$

Sesungguhnya fase prasekolah merupakan fase yang sangat penting untuk pertumbuhan akal anak lewat permainan yang dilakukan, dimana seorang anak sampai pada puncak kematangan berpikir dengan permainan.

Melalui permainan juga, anak akan mampu mengulangi kemampuankemampuannya terdahulu sampai ia bisa memahami dan menyerapnya dengan baik dan akhirnya menjadi bagian dari karakternya. Permainan juga dapat menyiapkan seorang anak untuk mampu beradaptasi dan bersosialisasi di masa depannya. Hal ini bisa lihat dari respons yang diberikannya selama bermain. Oleh karena itu, permainan tidak dapat dijadikan sarana hanya untuk menghabiskan waktu, tetapi sarana untuk membantu perkembangan anak. Para orang tua yang melarang anaknya bermain di rumah atau bersama anak-anak tetangganya, sama artinya dengan melarang anak dari kebutuhan asasi dalam perkembangannya.

\section{Pendidikan Pembentukan Intelektualitas Anak}

Dalam aktivitas membentuk keilmuan dan pola pikir anak, orang tua harus memperhatikan kaidah-kaidah dan prinsip-prinsipnya agar tertanam dalam diri anak ilmu dan pola pikir yang benar dan lurus. Karenanya, proses pembentukan keilmuan anak ini berhasil, maka kebaikan dan kebahagiaan akan dirasakan oleh orang tuanya. Jika sebaliknya, maka akan menjadi boomerang bagi orang tuanya dan kita berlindung kepada Allah darinya.

Jika kita perhatikan, prinsip-prinsip dalam pembentukan keilmuan seorang anak merupakan sebuah upaya dari dalam untuk mengarahkan anak tentang nilai

\footnotetext{
${ }^{11}$ Imam al-Ghazali, Al-Ihya fi 'Ulumu al-Din, Juz ke-3.

${ }^{12}$ Muhammad Ibnu Abdul Hafidh Suwaid, Manhaj Tarbiyah Nabawiya, h. 335-338.
} 
ilmu, belajar, dan mencintai ulama, sebagaimana pentingnya peran orang tua dalam memilihkan guru yang shalih dan shalihah untuk anaknya. Apa yang baik menurut pandangan seorang guru, akan baik menurut pandangan anak. Karena itu, mengetahui prinsip-prinsip untuk itu menjadi sangat penting bagi para orang tua. Prinsip-prinsip yang dimaksudkan adalah sebagai berikut:

1. Mengajarkan kepada anak untuk cinta kepada ilmu dan adab-adabnya.

2. Memberikan tugas hafalan ayat-ayat alquran dan hadis.

3. Memilihkan guru sekolah yang baik.

4. Mengajarkan bahasa Arab.

5. Mengajarkan bahasa asing.

6. Membimbing anak sesuai dengan kecondongan ilmiahnya.

7. Membuat perpustakaan di rumah.

8. Menceritakan kepada anak tentang kisah ulama-ulama besar yang semasa kecilnya rajin menuntut ilmu.

\section{Penutup}

Orang tua memiliki kewajiban untuk memelihara diri dan keluarga (anakanaknya) dari siksaan api neraka. Cara yang dapat dilakukan oleh orang tua ialah mendidiknya, membimbingnya dan mengajari akhlak-akhlak yang baik. Mengenalkannya pendidikan aqidah, ibadah, akhlak, pendidikan emphatik, pendidikan jasmani, pendidikan kesehatan, dan pendidikan intelektualitasnya.

Ya Allah, ya Robbana, karuniakanlah kepada kami anak-anak shalih atau shalihah yang dapat menjadi tabungan kami di dunia hingga di akhirat tatkala kami harus mempertanggungjawabkan hidup kami di hadapan-Mu ya Robbana. Tiada daya dan upaya kami, melainkan atas karunia-Mu juga ya Robbana. Karuniakanlah kepada kami anak-anak shalih atau shalihah yang menjadi penyejuk mata dan hati kami di dunia hingga di akhirat. Rabbana hablana min azwajina wa dzurriyatina qurrota 'ayuni waj'alna lilmuttaqina imaman. 


\section{Pustaka Acuan}

Abdussalam, Suroso. Strategi Menjadi Orang Tua Bijak dan Pintar Medokan: Sukses Publishing, 2012.

Al-Dimasyqi, Ismail Ibnu Katsir, Tafsir Al Qur'an al-Karim, Jilid 28, (Kairo: Maktabah Aulad al-Syaikh li at-Turats, 2000), h. 416.

Ghazali, Imam. Al-Ihya fi 'Ulumu al-Din, Juz ke-3.

Ismail SM (eds), Paradigma Pendidikan Islam, Yogyakarta : Pustaka Pelajar, 2001.

Patmonodewo, Soemiarti, Pendidikan Anak Prasekolah, Cet. II. Jakarta: Rineka Cipta, 2008.

Poerwanti, Endang dan Widodo, Nur, Perkembangan Peserta Didik, Cet. II. Malang: $\quad$ UMM Press, 2002.

Suwaid Muhammad, Ibnu Abdul Hafidh, Manhaj Tarbiyah Nabawiyah Lith Thifli, Edisi Indonesia, "Cara Nabi Mendidik Anak", Cet. II. Penerjemah: Hamim Thohari et al. Jakarta Timur: Al-'Itishom Cahaya Umat, 2008. 
